\title{
Advanced tubal ectopic pregnancy of 19 weeks gestation: case report and review of the literature
}

\author{
Ángel Lemus Huerta ${ }^{1}$, Junior Joel Araiza Navarro' ${ }^{2 *}$, Araceli Román Pompa ${ }^{3}$, \\ Oyuki Aricet Morales Uscanga ${ }^{4}$, Margarita Eugenia Pérez Chavira ${ }^{5}$, \\ Jorge Arturo Barbabosa Vilchis ${ }^{6}$
}

\begin{abstract}
${ }^{1}$ Associated Physician of Obstetrics and Gynecology of the Hospital General de Zona Francisco del Paso y Troncoso and Gynecologist-Obstetrician, Biologist of Human Reproduction, Department of Reproduction Biology of the Hospital General Naval de Alta Especialidad, Secretaría de Marina Armada de México (SEMAR)

${ }^{2}$ Gynecology and Obstetrics Resident at the Postgraduate School of Naval Sanity, Universidad Naval and the Hospital General Naval de Alta Especialidad, Secretaría de Marina Armada de México (SEMAR)

${ }^{3}$ Associate Physician of Obstetrics and Gynecology of the General Hospital of the Zone Francisco del Paso y Troncoso ${ }^{4}$ Gynecologist-Obstetrician, Chief of Residents the Surgical Area of the Hospital General Naval de Alta Especialidad, Secretaría de Marina Armada de México (SEMAR)

${ }^{5}$ Medical Pathologist Associated with the Pathology Service of the General Hospital of the Zone Francisco del Paso y Troncoso

${ }^{6}$ Gynecologist-Obstetrician, Colposcopist, Chief of the Department of Gynecology and Obstetrics of the Hospital General Naval de Alta Especialidad, Secretaría de Marina Armada de México (SEMAR)
\end{abstract}

Received: 29 August 2018

Accepted: 05 October 2018

\section{*Correspondence:}

Dr. Junior Joel Araiza Navarro,

E-mail: joelara16@hotmail.com

Copyright: (C) the author(s), publisher and licensee Medip Academy. This is an open-access article distributed under the terms of the Creative Commons Attribution Non-Commercial License, which permits unrestricted non-commercial use, distribution, and reproduction in any medium, provided the original work is properly cited.

\section{ABSTRACT}

Ectopic pregnancy is a condition in which the fertilized ovum is impacted anywhere other than the uterine cavity, these sites may be uterine tubes, cervix, ovary and abdomen. Ectopic implantation in the uterine tubes occurs up to 98\%. The distribution according to its location is: $78 \%$ ampullary, $12 \%$ isthmic, $5 \%$ fibrous, $2-3 \%$ interstitial, $1 \%$ ovarian, $1-2 \%$ abdominal, and more rare in cervix with $0.5 \%$. Ectopic pregnancy occurs 1.2 to $2 \%$ of pregnancies, with an associated mortality of 0.5 deaths per 1000 pregnancies. There are multiple risk factors for an ectopic pregnancy, among the most frequent are: women with pelvic inflammatory disease (salpingitis) conditioned mainly by Chlamydia trachomatis and Neisseria gonorrhea, anatomical abnormalities of the tubes, previous surgery in them (including sterilization), masses extrinsic tumors that compress them, endometriosis, zygote anomalies, endocrinopathies (corpus luteum deficiency in late ovulation), use of intrauterine devices, previous ectopic pregnancy (as a result of surgical treatment or due to persistence of the original risk factor), contraceptive users with gestagens in low doses, assisted reproduction techniques, smokers, secondary adhesions to surgical interventions on the uterus, ovaries, and other pelvic or abdominal organs, exposure of the uterus to diethylstilbestrol, among others. The objective of this case is to describe an advanced tubal ectopic pregnancy. The following case report is about a 24year-old patient with a pregnancy of 19 weeks of gestation by first-trimester ultrasound and a history of recent laparoscopic cholecystectomy secondary to biliary lithiasis. He is in the first trimester of normo-evolutive and without symptoms. Authors present to the emergency department with a 24-hour abdominal pain syndrome that requires exploratory laparotomy and right salpingo-oophorectomy due to the presence of ruptured tubal ectopic pregnancy with average fetometry of 19 weeks of gestation. The patient is discharged after an adequate clinical evolution.

Keywords: Painful abdominal syndrome during pregnancy, Tubal ectopic pregnancy 


\section{INTRODUCTION}

Ectopic pregnancy is defined as the implantation of the blastocyst anywhere outside the endometrial cavity. ${ }^{1}$ It is a frequent complication of pregnancy and its importance is that it represents approximately 6\% of all maternal deaths, being the main cause of maternal death in the first trimester. ${ }^{2,3}$ In Mexico, the prevalence of ectopic pregnancy is reported in 1 to 200 to 1 to 500 pregnancies, of these more than $95 \%$ are tubal pregnancies: $50 \%$ in the ampulla, 20\% in the isthmic region and the rest in the infundibulum, fimbria or interstitial portion. ${ }^{3}$

With the development of pregnancy, a tubal ectopic pregnancy can have different results: spontaneous resolution or rupture; with a significant impact on patient morbidity and mortality. ${ }^{4}$ The clinical presentation of an unruptured ectopic pregnancy has nonspecific manifestations that may be present in a normoevolutionary pregnancy. A ruptured ectopic pregnancy is a medical emergency with signs and symptoms of hemodynamic shock. For this reason, one of the key steps during pregnancy is to determine if it is an intrauterine pregnancy. ${ }^{2}$

The diagnosis of a tubular ectopic pregnancy is made at an average gestational age of $6(+1.5)$ weeks of gestation, varying between 5 and 10 weeks of gestation. ${ }^{5,6}$ The size that is known to reach a tubal pregnancy before breaking is about $1.5-3.5 \mathrm{~cm}$, after this size, the growth inside the uterine tubes would cause the rupture of them, due to the absence of elastic muscle fibers in these. ${ }^{7}$

Reports have been made of advanced tubal ectopic pregnancies, such as that of Sachan, of a tubal ectopic pregnancy of 14 weeks' gestation, measuring $10 \times 12 \mathrm{~cm}$, confirmed by laparotomy and resolved with left salpingooophorectomy. ${ }^{8}$ The case report with the older gestational tubal pregnancy that was found was reported by Nkwabong presenting a pregnancy of 25.6 weeks of gestation in the right uterine tube, no longer viable. ${ }^{9}$

In this report, authors present the case of a patient with a tubal ectopic pregnancy that reached 19.6 weeks of gestation with reports of a prenatal control corresponding to an uncomplicated pregnancy, associated with clinical manifestations of a painful abdominal syndrome.

\section{CASE REPORT}

A 24-year-old female patient with a history of laparoscopic cholecystectomy secondary to symptomatic biliary lithiasis one month before, with no other relevant antecedents for the current condition. She goes to the emergency department referring to her being her first pregnancy and having 17.3 weeks of gestation by ultrasound of the first trimester and date of the last type II menstruation. It presents a 24-hour evolution characterized by intense, diffuse abdominal pain, aggravated by movement and in the dorsal decubitus position. It is associated with rectal tenesmus and constipation of four days of evolution. Denies transvaginal bleeding.

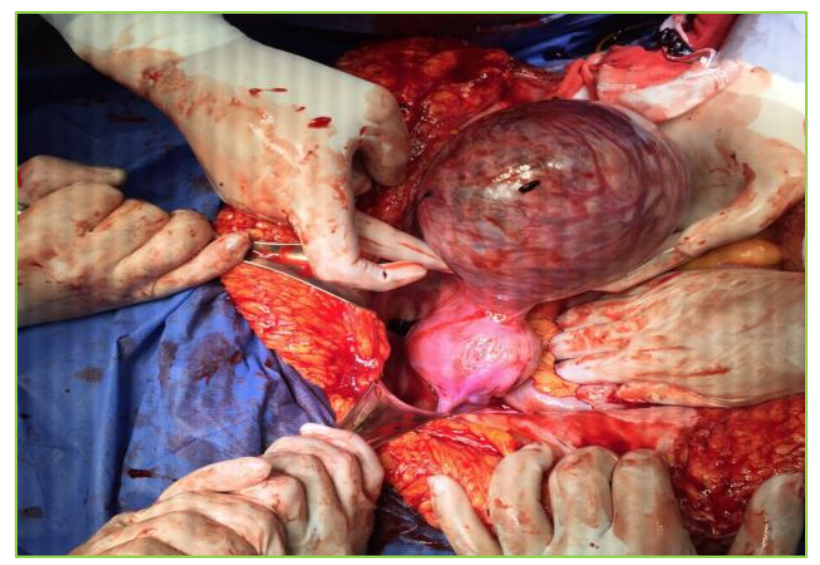

Figure 1: Tumoration in right uterine tuba corresponding to ectopic pregnancy of 19.6 weeks of gestation.

Upon admission, it presents with facial facies, agitation, pallor of teguments, tachypnea and orthopnea, dehydration data. At the abdominal level, with a globose abdomen at the expense of adipose panniculus, muscular resistance, superficial and deep palpation pain, negative decompression, uterus with normal tone and without activity; Fetal heart rate of 135 beats per minute; vaginal touch with posterior cervix, closed and without corroborated transvaginal losses.

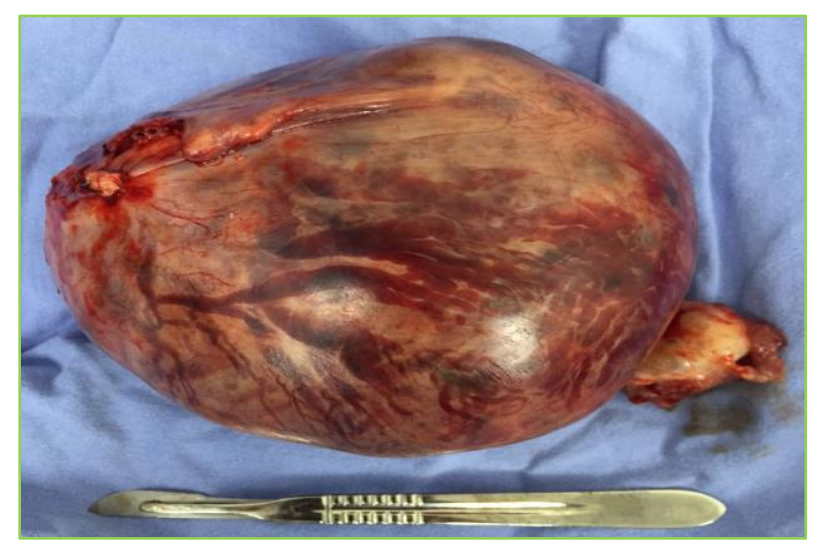

Figure 2: Product of ectopic pregnancy of 19.6 weeks of gestation prior to its dissection.

The Toco-Surgical Unit was admitted with a diagnosis of abdominal pain syndrome in a study associated with severe sepsis secondary to the following differential diagnoses: intestinal perforation, intestinal occlusion and metabolic ileus.

Laboratory tests show the following values: hyperglycemia $(132 \mathrm{mg} / \mathrm{dL})$, urea $25.68 \mathrm{mg} / \mathrm{dL}$, urea nitrogen of $12 \mathrm{mg} / \mathrm{dL}$, hyponatremia $(133 \mathrm{mmol} / \mathrm{L})$, normocytic normochromic anemia (hematocrit of $24.9 \%$, 
hemoglobin of $8.3 \mathrm{~g} / \mathrm{dL})$, leukocytosis at the expense of Neutrophilia (33.9 x 103), neutrophils 83\%), compensated metabolic acidosis $(\mathrm{pH} 7.3$, partial pressure $\mathrm{CO}_{2} 31 \mathrm{mmHg}$, sodium bicarbonate $15.3 \mathrm{mmHg}$ ).

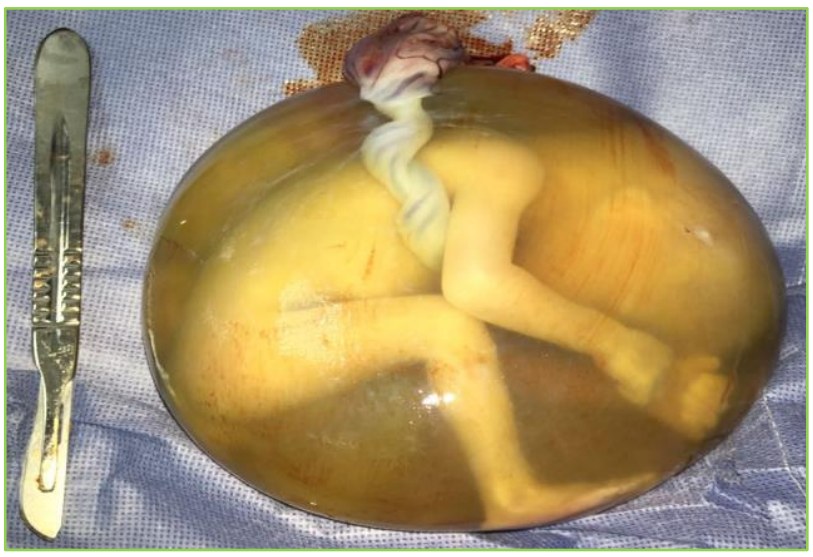

Figure 3: Product of ectopic pregnancy of 19.6 weeks of gestation inside fetal membranes.

The simple abdominal radiograph shows compatible data with presence of abundant fecal matter and distension of bowel loops. Abdominal ultrasound reports right subphrenic free fluid, findings suggestive of functional colonic disorders and surgical absence of gallbladder. In the obstetric ultrasound is determined: pregnant uterus with unique product, live and intrauterine, well formed, in a non-definitive variable situation, with active body movements, preserved fetal attitude, with a heart rate of 140 beats per minute, encephalon and neural axis without alterations, high posterior body placenta without evidence of bruising or detachment, amniotic fluid of normal volume for gestational age, average fetometry of 19.6 weeks of gestation. Intramural myoma is identified in the anterior wall of the cervical segment measuring $5.2 \times 4.5$ x $7.2 \mathrm{~cm}^{3}$, urinary bladder with urinary sediment. Additionally, a giant subcapsular hematoma at the hepatic level is revealed by simple abdominal tomography.

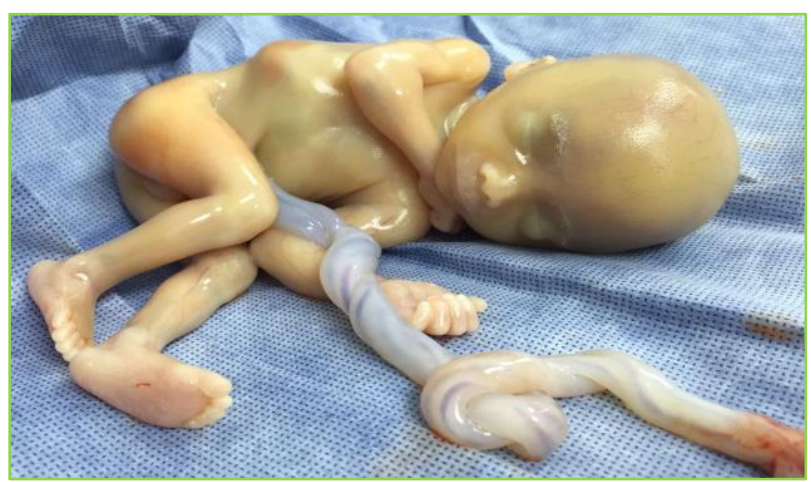

Figure 4: Product of ectopic pregnancy of 19.6 weeks of gestation.

Urgent exploratory laparotomy is performed with general anesthesia. The surgical approach consists of a bilateral subcostal incision (Chevron) and a second midline incision. A ruptured right tubal ectopic pregnancy requiring right salpingo-oophorectomy is observed. Male newborn of 300 grams is obtained, with intact fetal membranes. It is estimated that $1500 \mathrm{cc}$. A second exploratory laparotomy is performed secondary to the presence of blood content in Penrose drainage. Hemostasis of bleeding pedicle is ensured.

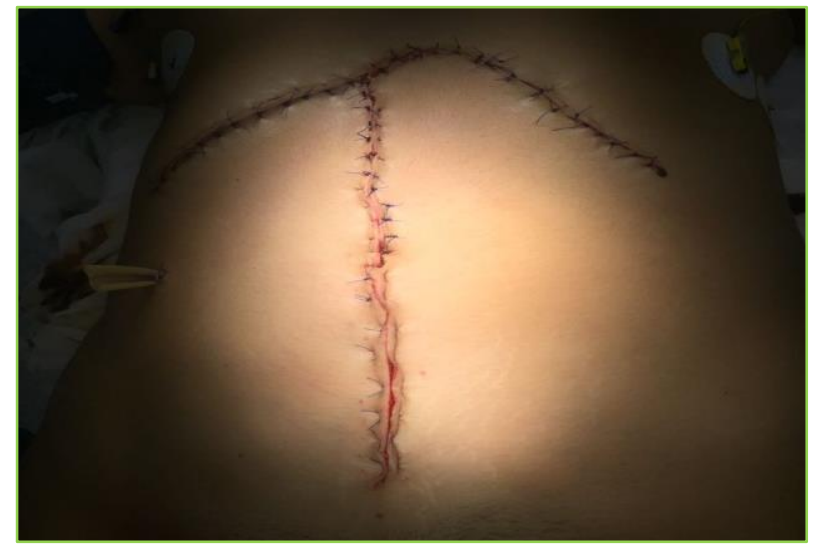

Figure 5: Surgical incisions performed for diagnostic abdominal cavity exploration.

She is admitted to the Intensive Care Unit, where the following final diagnoses are established: female of 24 years, with gestation 1 and abortion 1, postoperative of exploratory laparotomy and right salpingooophorectomy, hypovolemic shock grade IV secondary to ectopic tube-ovarian pregnancy broken, normocytic normochromic anemia and metabolic acidosis.

The patient leaves the Medical Unit after presenting an adequate clinical evolution.

\section{DISCUSSION}

The tubal pregnancy is a consequence of the abnormal transport of the embryo and of an alteration in the environment of the uterine tubule that favor an abnormal implantation. Despite the existence of multiple known risk factors that may favor this pathology, up to $50 \%$ of patients who present it have no identifiable. ${ }^{10}$

In this case, the patient did not present any risk factor or early clinical manifestation that could be correlated with the presence of an ectopic pregnancy. However, although this pregnancy was categorized as normo-evolutive according to the medical management prior to the abdominal pain, there is a failure in the early diagnosis. This may be due to the fact that it is an atypical tubular ectopic pregnancy characterized by the absence of clinical evidence such as transvaginal bleeding or abdominal pain during the first trimester; or due to the lack of an endovaginal ultrasound -a key in the prenatal control- that shows the abnormal implantation of the product and that, associated with repeated tests of 
chorionic gonadotropin hormone, reaches a value of diagnostic sensitivity greater than $90 \%$.

It is important to mention that in an ectopic pregnancy greater than 12 weeks of gestation; the ultrasound study may no longer be diagnostic and prolong the interruption thereof with serious consequences such as rupture and hemodynamic instability. ${ }^{2,9}$ The computed tomography is avoids during pregnancy due to exposure to radiation of the fetus and, although an MRI study could be performed as an alternative, the patient's hemodynamic instability, limited access to imaging studies such as MRI in our environment, allow us to consider the usefulness of the abdominal tomography in pregnant women with abdominal pain and without transvaginal bleeding, in order to rule out differential diagnoses such as pancreatitis or appendicitis that could simulate a rupture of the ectopic pregnancy.

The definitive treatment is the interruption of pregnancy by laparoscopy or laparotomy that also allows the realization of the definitive diagnosis of ectopic pregnancy. ${ }^{4,5}$ It should be noted that, unlike other cases where the resolution ends with a hysterectomy, in this patient a right salpingo-oophorectomy was performed, preserving the possibility of a new pregnancy.

The importance of this report lies in two main points: the previous cases reported in the international literature have described long-term ectopic pregnancies; but this case represents one of the viable tubal pregnancies with greater gestational age. The second and even more important, the repercussions on the patient, secondary to the progression of the condition such as a major surgical intervention, the termination of pregnancy and gestational loss. In developing countries, the lack of access to diagnostic methods, inadequate prenatal control or atypical presentation of ectopic pregnancy make the diagnosis of these pictures more frequent when there is rupture and, consequently, serious alterations in morbidity and mortality of the patients.

\section{CONCLUSION}

Tubal ectopic pregnancy represents one of the main complications in the first trimester of pregnancy. The progression of an ectopic pregnancy to more advanced stages is rare and has consequences that include infertility, recurrence of ectopic pregnancy and even death. It is recommended to improve in the prenatal control of the patients with the main emphasis in determining the exact location of the implantation of the embryo in the earliest stages of pregnancy. Despite having reports of a normo-evolutionary pregnancy, each health professional should corroborate the location of the pregnancy at the first prenatal visit.

Also, always consider the likelihood of an ectopic pregnancy in a patient with acute abdomen, regardless of the weeks of gestation.

Funding: No funding sources

Conflict of interest: None declared

Ethical approval: Not required

\section{REFERENCES}

1. Guerrero-Martínez E, Rivas-López R, MartínezEscudero IS. Some demographic aspects associated with ectopic pregnancy. Gynecol Obstet Mexico. 2014;82(02):83-92.

2. Barnhart KT. Ectopic pregnancy. New England J Med. 2009;361(4):379-87.

3. Clinical practice guide: Diagnosis and treatment of tubal pregnancy, CENETEC- IMSS-182-09.

4. Varma R, Gupta J. Tubal ectopic pregnancy. BMJ Clinical Evidence. 2012;2012.

5. Simsek Y, Ay MO. Analysis of ectopic pregnancies admitted to emergency department. Turkish J Emerg Med. 2015;15(4):151-4.

6. Pradhan P, Thapamagar SB, Maskey S. A profile of ectopic pregnancy at nepal medical college teaching hospital. NMCJ. 2006;8(4):238-42.

7. Kim M. Unusually large, unruptured tubal ectopic pregnancy mass in a woman with bilateral tubal obstruction treated by laparoscopy: a case report. J Med Cases. 2016;7(9):396-8.

8. Sachan R, Gupta P, Patel ML. Second trimester unruptured ampullary ectopic pregnancy with variable presentations: Report of two cases. IJCRI. 2013;3(8):1-4.

9. Nkwabong E, Tincho EF. A case of a 26-week ampullary pregnancy mimicking intrauterine fetal death. Anatolian J Obstet Gynecol. 2012;1(1).

10. Panelli DM, Phillips $\mathrm{CH}$, Brady PC. Incidence, diagnosis and management of tubal and nontubal ectopic pregnancies: a review. Fertil Res Pract. 2015;1(1):15.

Cite this article as: Huerta AL, Navarro JJA, Pompa AR, Uscanga OAM, Chavira MEP, Vilchis JAB. Advanced tubal ectopic pregnancy of 19 weeks gestation: case report and review of the literature. Int J Reprod Contracept Obstet Gynecol 2018;7:4794-7. 